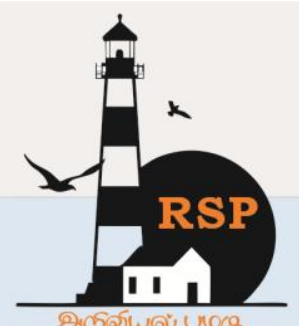

INTERNATIONAL RESEARCH JOURNAL ON ADVANCED SCIENCE HUB

ISSN : $2582-4376$
Open Access

RSP SCIENCE HUB

(The Hub of Research Ideas)

Available online at www.rspsciencehub.com

Special Issue of Second International Conference on Advancements in Research and Development (ICARD 2021)

\title{
E-RTO Management System
}

Abinash $M^{1}$,Gokilavani $V^{2}$, Jana Priya $S^{3}$, Shobana $M^{4}$,Sangeetha $K^{5}$

${ }^{1,2,3}$ UG Scholar, Department of Computer Science and Engineering, SNS College of Technology, Coimbatore, India.

${ }^{4,5}$ Assistant Professor, Department of Computer Science and Engineering, SNS College of Technology, Coimbatore, India.

jana24priya@gmail.com ${ }^{1}$, goilvanivellingiri99@gmail.com ${ }^{2}$, abinashm19@gmail.com ${ }^{3}$, shobanavsm@gmail.com ${ }^{4}$,sangithaprakash@ gmail.com ${ }^{5}$

\begin{abstract}
RTO office the executives framework project is ready for RTO office to keep up all records like vehicle enlistments, LMV, HMV, learning permit and driving permit, changing of address, reestablishment structure, charge challans and getting instalments against challan and substantially more. These are the primary exercises of RTO office. This instrument has been intended to encourage the progression of data inside the association. In the Previous System It isn't proficient in performing office work in RTO administrations, It incorporates a lot of manual cycle and tedious, It isn't easy to use, Maintains nearby information base. The current framework isn't giving exact outcomes while doing exchanges. It doesn't give security, anybody go into the framework and can do their own exchanges. It isn't adaptable in producing reports and numerous manual cycles are made modernized. To beat issues in the current System another RTO administrations "RTO OFFICE MANAGEMENT SYSTEM" is proposed after investigation of framework. The goals of proposed framework are: Ensure information trustworthiness and security, less labour, Generate precise reports, Accurate dealing with in various subtleties.
\end{abstract}

Keywords: RTO management system, Data security and integrity, Vehicle registration

\section{Introduction}

As the name suggests, the RTO(Regional Transport Office) framework is an application that is intended for the RTO for the interaction of enlistment of vehicles and giving driving license measure and numerous more. It is a mechanization of street office through cell network. It can cause the everyday exercises to run proficiently to and give quick reaction to recover and store the information.RTO the executives framework can likewise go about as a main mechanical instrument for the simplicity of RTO capacities like enrolment student's permit and wellness etc. It will lessen impressively the challenges looked on existing framework with least blunder and difficulties. This task will assume a main part in diminishing specialized troubles looked in everyday exercises that are diverted in the RTO to run smoothly. You can see tremendous load of records that are being accumulated in the RTO offices. The UI should be basic and straightforward even by the comman man. There are numerous highlights which is accessible in our framework like vehicle registration, learners license, renewal etc..The monotonous positions, for example, checking every one of the records of the applicant, confirming every one of the individual subtleties are furnished, submission 
of capability documents, driving license enlistment details, etc are done in the most convenient path to the administrator. All the halfway stages beginning from accepting of tech applications structure to uncovering the candidate number alongside tech expiry date of the permit are being delat. This innovation empowers the traffic police to be more successful in controlling recurrent violators of traffic rules. Traffic Police have the information base of enlistment numbers just as the historical backdrop of driving permit holders. At the point when a traffic police officer would enter the subtleties of any vehicle discovered abusing traffic rules, it would give the complete details of that specific vehicle including the name and address of proprietor and the make, model and different subtleties of the vehicle. Not just this, the subtleties of the driving permit holder would likewise be accessible. Subsequently improved punishments would be forced for reiteration of infringement of traffic rules. Counterfeit enrolment plates, assuming any, future identified right away [1-5].

\subsection{Problem statement}

In this day and age with the expanding traffic and longer driving distances it is getting hard for individuals to go for their specific licenses issue. Also a large portion of individuals today work for longer hours and don't have the adaptability to take a break from work to give the licenses tests. People possess not burned through more effort for licenses test. The People need an office where they can have simple to give their licenses. The office to accomplish plan date by SMS, call or mail. As a complete labour based framework is at present running for the entire methodology which requires part of time and paper work. To defeat this problem, proposed an online framework to keep up all records of LL,DL, Vehicle registration, renewal etc. once all these get mechanized to work effectiveness of the representative will get increments.

\subsection{Objective}

It is needed to construct another site as per RTO office framework and facilities. so that everything individuals can get the data about the interaction to be helded in the RTO office. The principle reason for this venture is to assemble an application program to diminish the manual work for dealing with the vehicle, registration, taxes etc. It tracks every one of the insights regarding the client vehicle. we have utilized ASP.NET and SQL worker innovation to make solid and got data set availability. .It can cause the day by day exercises to run proficiently to and give quick reaction to recover and store the information.RTO the board framework can likewise go about as a main mechanical instrument for the simplicity of RTO capacities, for example registration, learner's license, and wellness etc. By his framework public can save their significant time and money. It additionally encourages the labourers to finish their work effectively [6-10].

\section{Feasibility study}

An achievability study is a starter study attempted to decide and record a task's practicality. The term achievability study is likewise used to allude to the subsequent record. These after effects of this examination are utilized to settle on a choice whether to continue with the venture, or table it. On the off chance that it for sure prompts an undertaking being endorsed, it will - before the genuine work of the proposed project begins - be utilized to discover the probability of the venture's prosperity. It is an examination of conceivable elective answers for an issue and a suggestion on the best other option. It, for instance, can choose whether a request handling be completed by another framework more effectively than the past one. A attainability study could be utilized to test a proposition for new framework, which could be utilized in light of the fact that The current framework may at this point don't convey motivation, Technological progression may have delivered the current frame workout of date, The business is growing, permitting it to adapt to additional responsibility Customers are griping about the speed and nature of work the business gives, Competitors are presently winning a large enough piece of the pie because of a viable reconciliation of an automated framework.

\section{Proposed System}

Here, we are building up a web application for RTO so here we give a concise depiction of our 
undertaking outline. To give recognizable climate implies the poor client can get to this site for their work reason identified with RTO. First client needs to fill the enrolment structure so we give verification to him and afterward client can pick alternative he needs implies on the off chance that he select to making a driving permit, we give driving permit prerequisite subtleties and give accessible date to him so he please that date direct give the test so he can save his time just as cash. On the off chance that client needs to pass his vehicle number, likewise it requires some serious energy in old framework however here we give office that client he purchase new vehicle he ought to need to initially enrol on our site and fill all the required and significance subtleties of vehicle and we gives this subtleties to RTO office straightforwardly so this work will get total inside less time and the client get his number layout without any problem. The overseer is accommodating verification reason just as it handles all the data set of RTO and deals with all the cycle. He has power to affirmed learning permit number, perpetual permit number; pass the vehicle enlistment number, and so forth Offices are given by the head

\section{Conclusion}

It very well may be presumed that our undertaking "E-RTO Management System" which is an Automation of Road Transport Department through Cellular Network was effectively evolved and tried by our group. Our framework presents an office for the RTO Officers to perform confirmation of the License and Vehicle records electronically. It will likewise help the RTO authorities to keep up records deliberately and decreases a great deal of administrative work and manual endeavors. We additionally distinguished some broad necessities of such a framework and attempted to meet those prerequisites however much as could be expected in the plan and usage of our system. In future, according to the clients necessity our entire Program was planned. It gives a superior method of report check for RTO authorities. Our framework is an incorporation of a few frameworks that in present go about as a different framework. The future framework Maintains detail data of Driving License, Vehicle Registration, Emission and Insurance data of related vehicle. It will likewise diminish a great deal of administrative works and gives better responsibility. A different sms door can likewise give fine warning messages at the flex module

\section{Application}

1. The proposed framework encourages the simplicity of tasks.

2. It guarantees the information honesty and security.

3. It diminishes the labor and assists with finishing the work effectively.

4. It produces exact reports.

5. Accurate dealing with in numerous subtleties of various clients.

\section{References}

[1].Bazghandi, "Web Database Connectivity Methods (using Mysql) in Windows Platform", in Information and Communication Technologies, 2009, pp. 3577 - 3581

[2].Juszkiewicz, "The use of Adobe Flex in combination with Java EE technology on the example of ticket booking system", in CAD Systems in Microelectronics (CADSM), 2011, pp. [317 - 320]

[3].Manjunath S Patil, Basavaraj K Madagouda, Vinod C Desai "E-RTO Management System" in IJERT ISSN:2278-0181 V21S70177 Vol. 2 Issue 7, July-2013

[4].Narayan S. Rau, "Issues in the Path Toward an RTO and Standard Markets", IEEE TRANSACTIONS ON POWER SYSTEMS, VOL. 18, NO. 2, MAY 2003

[5].Norah Huda Y usuf, Rosilah Hassan, "Flash Notes and Easy Electronic Software (EES): New Technique to Improve Digital Logic Design Learning", in International Conference on Electrical Engineering and Informatics, 2011

[6]. Vijay S "A Study on Vehicle License Information Management and Processing System" International Journal of Engineering Science Invention (IJESI), Vol. 08, No.10, 2019, PP 50- 56

[7].Vijisha P.O, Dr. A.V Senthil Kumar, "RTO Office Management System", in International Journal Of Advance Research and Development, vol 2, Issue 3, 2017 
[8].Wan-Mi Chen, Y u- Cherg Chen, "Web design and implementation for remote control", in Intelligent Control and Automation (WCICA), 2012, pp. [920 - 924]

[9].Xiaosheng Y u, Yichang, China CAI Yi, "Design and Implementation of the Website Based on PHP \& "MY SQL", in E-Product EService and E-Entertainment (ICEEE), 2010, pp. [1 - 4].

[10].Yan Lin, Senior Member, IEEE, Gary A. Jordan, Mark O. Sanford, Jinxiang Zhu, Member, IEEE, and William H. Babcock, "Economic Analysis of Establishing Regional Transmission Organization and Standard Market Design in the Southeast", IEEE Transactions On Power Systems, Vol. 21, No. 4, November 2006 